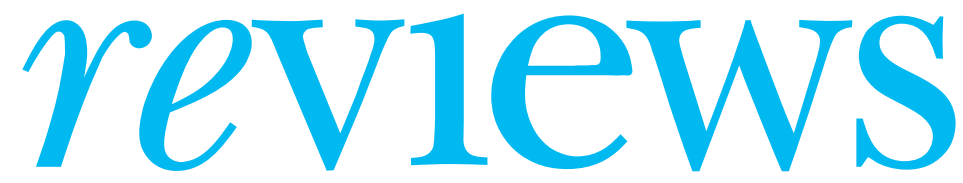

BOOKS • CD ROMS • ART •WEBSITES $\bullet$ MEDIA $\bullet$ PERSONAL VIEWS $\bullet$ SOUNDINGS

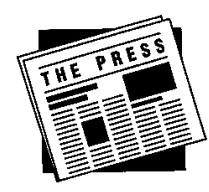

\section{The new MMR?}

Are the media stirring up a fresh autism scare?

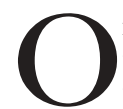

15 March the Daily Mail reported that a scientist had made some disturbing claims about a common three-in-one childhood vaccine. In a nutshell, it could cause autism. Campaigners were demanding that the vaccine be phased out forthwith, and replaced by an available alternative. The government was resisting their demands, arguing that the alternative was less effective.

More on MMR (measles, mumps, rubella), you might be thinking. All a bit passé, surely. But no-the vaccine in this case is against diphtheria, tetanus, and pertussis (DTP) and the alleged link with autism is supposed to be mediated by thiomersal, the mercury-based material used as a preservative in the version of the vaccine commonly administered in Britain.

The Mail's article wasn't the first outing for this story and, apart from a few paragraphs two days later in the London Evening Standard, it made few waves. This time too it could just die. Or, for any of a score of reasons, it may yet stagger to its feet and, in the manner of the MMR fiasco before it, trample another destructive path through the fields of childhood vaccination policy.

Thiomersal, a sodium salt of ethylmercury, has been used for 60 years. In north America and much of Europe it has been abandoned, and the Department of Health says that this country will follow suit, though it may take some time. Unlike the single vaccines used instead of the triple MMR, an alternative to the thiomersalcontaining DTP vaccine is apparently available through the NHS. But many people-including some general practitioners-are unaware of this. For the time being parents may be tempted to respond to this new perceived hazard in the way that many have to MMR: by not "risking" it.

The arguments for and against thiomersal are beyond the scope of this piece. The issue here is the part that journalists and campaigners play in driving these scares, and why.

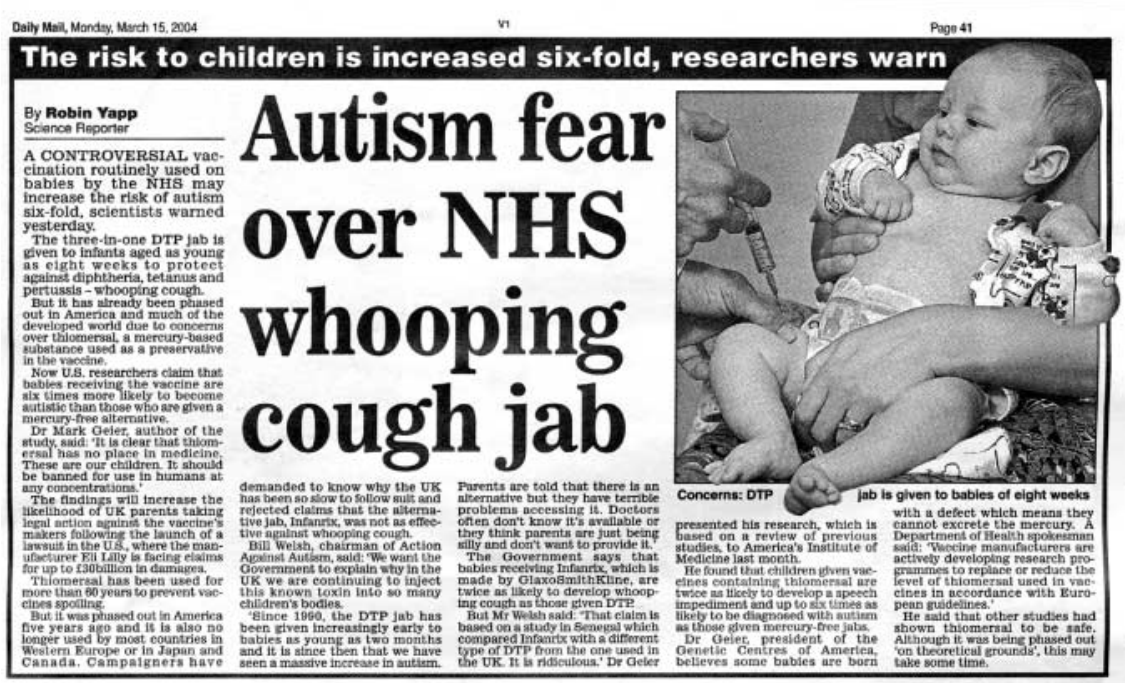

How the Dail Mail reported the claims about the DTP vaccine

Among the organisations protesting about thiomersal is the Glasgow-based Action Against Autism, a vocal opponent of MMR vaccination. Its chairman, Bill Welsh, told the Mail: "We want the government to explain why in the UK we are continuing to inject this known toxin into so many children's bodies."

Mindful of recent setbacks to the Wakefield hypothesis, cynics may suspect that Action Against Autism is now keen to hitch itself to a different anti-vaccination bandwagon. Not so. "Wakefield's case has not been blown apart," Mr Welsh insists. And, far from representing a change of tack, suspicions about thiomersal could be all-ofa-piece with the Wakefield theory. "We're looking at a cascade of events at the end of which the child becomes autistic. By giving mercury three times to a child under four months, you're giving three opportunities for damage to be done." And then a rhetorical question: "What happens when you inject three viruses into a child with very high toxin levels?"

So, for Action Against Autism, thiomersal is simply business as usual. But what of the Mail? Assuming the paper had no wish to launch a re-run of the MMR saga, I contacted the managing editor's office to ask what checks the paper had made with informed medical opinion in Britain about thiomersal, how it viewed the possibility of parents who had read the piece deciding not to vaccinate their children at all, and what responsibility it felt when reporting isolated or unproven views on potentially controversial medical issues. Despite a phone call, an email, and four more calls I received no replies.
While offering no apologies for the Mail's unresponsiveness, it does have to be accepted that reporting the exceptional rather than the commonplace is one of the elements of news journalism. Established vaccines only become a story when they are suspected of creating problems as well as solving them.

The MMR affair prompted a great deal of speculation about the role of the media in fuelling medical scares. It also threw up a revealing survey carried out by researchers at the Cardiff University School of Journalism, who reviewed 561 stories on MMR published during 2002 (BMJ 2002;325:603). While many of these stories featured the case for a causal link and the case against it, what didn't come across was the huge imbalance between the strengths of the two cases. The researchers said that the sheer frequency with which the alleged autism link was reported led many readers to conclude that doctors themselves must be having a real debate about it. And if there wasn't a debate, why was it so often reported?

As for thiomersal, the measure of the risk that it imposes-if any-remains unclear; nor do we yet know if it will be widely perceived as risky.

Meanwhile, American manufacturers are facing a multi-billion dollar lawsuit. The one certainty in all this is that drug companies' already much-diminished enthusiasm for developing new vaccines will not be boosted.

Geoff Watts freelance medical journalist 


\section{Punishment by process}

$\mathrm{O}$

n Monday 1 March I tore open a white envelope, anxious to devour the contents. The envelope bore the distinctive insignia of the General Medical Council. I was soon to discover whether I would be facing a public hearing.

Back in $1989 \mathrm{I}$ had agreed to be the local coordinator for a multicentre randomised controlled trial of negative pressure support for preterm infants with respiratory distress, to reduce the number of babies developing serious chronic lung disease. During the study, which ran to August 1993, I had no cause for concern about any aspect of the trial. The results were published in Pediatrics in December 1996.

\section{Hit parade}

bmj com

These articles scored the most hits on the BMJ's website in the week of publication

\section{JANUARY}

1 Paper: Cigarette tar yields in relation to mortality from lung cancer in the cance prevention study II prospective cohort, 1982-8 BMJ 2004;328:72

5110 hits

2 Editorial: Radical surgery for mesothelioma BMJ 2004;328:237-8

5056 hits

3 Clinical review: Science, medicine, and the future: Omega 3 fatty acids and cardiovascular disease-fishing for a natural treatment BMJ 2004;328:30-5 4763 hits

4 Clinical review: Science, medicine, and the future: Is folic acid the ultimate functional food component for disease prevention? BMJ 2004;328:211-4 4210 hits

5 ABC of smoking cessation: Why people smoke BMJ 2004;328:277-9 4114 hits

6 Obituary: Harold Shipman BMJ 2004;328:231 3894 hits

7 Editorial: Health tsars BMJ 2004;328:117-8 3456 hits

8 Paper: Long term mortality after severe starvation during the siege of Leningrad prospective cohort study BMJ 2004:328:11 3277 hits

9 News extra: Parents discover their stillborn babies are alive four months after birth BMJ 2004;328:248-C 3246 hits

10 Editor's choice: "Let food be thy medicine ..." BMJ 2004;328:(24 January) 3214 hits
The complaints started in August 1994. Initially these were dealt with by discussion with concerned parents and written responses through the hospital's complain procedure. But then a campaign was launched in the local press in 1997 inviting parents who had children in the trial to contact a local solicitor. Complaints were sent to a wide range of bodies, including the police, coroner's office, health department, and the health authority. Attempts to answer complaints led to further questions.

One of the most serious allegations, which appeared repeatedly in the media, was that babies were studied without parental consent and that signatures on the consent forms were forged. As a response to mounting pressure an inquiry (resulting in the Griffiths report) was set up in December 1998. I was invited to the inquiry for voluntary interview twice in 1999.

The first interview was relaxed, but the second was conducted aggressively. I had no advance notification of questions, nor was I offered representation. I had no idea that my personal conduct would be scrutinised, because the inquiry did not stick to its original remit. The testimony of complainants was accepted at face value and not checked against hospital notes. None of the doctors who witnessed consent forms was invited to testify. The report, which criticised my personal conduct, was published in May 2000. I was not given the opportunity to see the report before publication to correct any errors.

The report and supporting documentation were passed to the GMC, which undertook a survey of all the parents of the babies in the study, asking them to verify signatures on the consent forms. The trust conducted its own investigation, involving an independent expert, and the police also undertook investigations, but neither found any evidence of misconduct or criminal activity.

The GMC's involvement became overt from March 2001, when I received a series of letters asking me to comment on affidavits from four sets of parents. I learnt in December that three cases were to go before the GMC's preliminary proceedings committee. Questions were also raised about the results of the GMC survey. The allegations were vague and non-specific, and serious professional misconduct was not defined.

In January 2002 the preliminary proceedings committee decided not to refer the cases to the professional conduct committee. Life could return to normal-or so I thought. But as a result of further complaints the GMC decided that it had made an error. Under threat of possible judicial review the GMC determined to re-examine two of the cases, a decision I learnt about through the local press. The GMC also claimed to have forgotten one case not previously referred to the preliminary proceedings committee.

More "supporting evidence" was received by the GMC for comment-more than 3000 pages, including detailed criticism of every aspect of the study and the management of the patients. Thus more than two years later I again held an envelope in my hand. The judgment: "not to refer and no further action to be taken." Was this truly the end? It's hard to believe, but I am now in the happy position of being found "not guilty as charged."

My experience raises several important issues. The Griffiths report did nothing to help either the complainants or doctors. The real agenda seems to have been the introduction of a research governance framework. Such inquiries must use a properly defined framework so that:

- The inquiry sticks to its remit

- The individuals involved are given proper representation

- The rules of evidence are followed, and

- Those affected by the report can comment on errors of fact before its publication.

Where several agencies are involved in dealing with complaints they should work together to ensure rapid resolution. Protracted investigation destroys professional practice and does not allow complainants to move on. A set period of not more than a year should be set for evidence to be collected, and if none is found the case should be closed.

Doctors should not be disadvantaged by errors in process made by the GMC. The new clinical awards system bars doctors from applying while under investigation. This makes doctors guilty until proved innocent. The spotlight of the media on complaints that might prove unfounded undermines patients' confidence; perhaps cases under consideration by the GMC should be sub judice.

Doctors have a responsibility to accept scrutiny, but it is in the interests of patientsand children in particular-that scrutiny is kept within reasonable bounds, otherwise dedicated professionals are seriously disabled in undertaking their duties and future doctors may be dissuaded from working in the more difficult areas of practice.

$\overline{\text { Andrew Spencer }}$ consultant paediatrician and reader in neonatal medicine, University Hospital of North Staffordshire NHS Trust, Stoke-on-Trent Andy.spencer@uhns.nhs.uk

Travelling into Trouble: Disgusting Diseases. A review of a television programme about tropical infections is available on bmj.com 


\section{Parents as well as children need protection}

I

$t$ is now some decades since the growing awareness of the different types of child abuse fundamentally changed the work of consultant paediatricians and of social workers. The idea grew that the protection of the child should take precedence over all other considerations, but this idea presupposes a well functioning system in which authority figures such as consultant paediatricians make few major mistakes.

The 1987 inquiry into the Cleveland sex abuse scandal, when dozens of children were taken from their families, showed that opinion regarding physical signs could be deeply divided, and the inquiry and subsequent episodes emphasised the damage that could be caused to families through ill considered opinion or action. In January 2003 Lord Laming, in the inquiry into the Victoria Climbié case, made numer-

I saw no mention of safeguards for parents ous recommendations. These concerned health care and actions by professionals, but in the summary of the inquiry that the Royal College of Paediatrics and Child Health produced for paediatricians I saw no mention of safeguards for parents.

From the legal point of view it is notable that the health authority or NHS trust has no duty of care to the parents while their child is in its care. This leaves the parents with little opportunity for redress. To the lay person the proposal that the child may in due course bring a retrospective action, but only for damage that the child may have suffered through negligence, does not seem to be of immediate relevance.

Retirement and having become a grandfather seem to have changed my focus. I find it difficult to accept that the only steps usually open to parents are to make a complaint to the very organisation concerned (until the organisation eventually agrees to allow an independent inquiry) or to try to obtain a judicial review (which is beyond the means of many parents). The only alternatives-appeal to the health ombudsman or complaint to the General Medical Council-are somewhat remote. Parents have to answer serious charges by a number of authority figures unaided, unrepresented, and in a potentially frightening environment. Even if an accused parent or carer were to have good answers to mistaken or unsupported charges by senior figures, there would still be a likelihood that the social services would retain a degree of suspicion or uncertainty. At the least this suspicion might result in placement of the child on the at-risk register, possibly with restriction of visiting or other orders. Does this matter?

A case involving a family I know well emphasises the power that paediatricians have, compared with that of social services and parents, irrespective of the merits of the occasion. parents' version of events. In this case the nursing staff may well have found the care of the child quite challenging: the child was still on a ventilator three years after a catastrophic neonatal illness but was making developmental progress and needed increasing mobilisation. The increased activity resulted in repeated temporary disconnections from the ventilator, each of which had to be reported and investigated.

For whatever reason, the paediatrician had formed the view that the original illness-for which no cause had been foundmay have been caused by the parents and had set investigations in train. The repeated disconnections were now regarded as attempts by the mother to harm her son, despite the fact that the nursing and medical notes showed that on eight of 10 disconnections over a period of two months she was not present. Child protection proceedings were triggered on the last

Social services had to act on the paediatrician's account of the suspicions. Further observation, police investigation, and a forensic psychiatrist's report found no evidence of actual or intended child abuse, but not before the family had suffered severe stress, in fact just short of tragedy. The parents' account was later vindicated by the withdrawal of a nurse's accusatory report, as having been "mistaken."

The Royal College of Paediatrics and Child Health recently expressed its concern that paediatricians are coming under stress from accusations linked to child protection. This suggests to me that all may not be well in a wider field, but it could be that not all the faults rest with the public. Such proceedings are inevitably stressful, and professional training and retraining would appear to be the best way forward, as Lord Laming and others have recommended.

It would also be helpful if accused parents due to face powerful professionals in a potentially intimidating environment had the right to submit the relevant papers to an independent professional and that an alternative view of the situation, if so held, could be presented. There are few other circumstances where an accused person risks (for them) such a serious outcome without representation.

I do not believe that such a measure would shield parents who abuse their children, as the parents' representative would need to be an experienced and independent professional in good standing, and it would help the maintenance of best practice in child protection work. Professionals who chair child protection conferences might welcome the opportunity to have additional opinions available when they have to make a decision in the face of uncertainty.
SOUNDINGS

\section{Fast forward?}

Hours in training? Never really thought about it, mainly because it was never an issue. About 5500 hours? Sound about right, for the first year at least? Probably: about 90 on a good week; 120 or more with the weekend on call; and let's just ignore the really bad weeks, when one's co-resident on a pair of wards was off on holiday: weeks that, however dire, could at least never go beyond 168 .

Not sure about the training, though For most of us, the goals were endurance, survival, and the avoidance of disaster, along with the slim possibility of being noticed favourably - clearly a help with one's later career. So, training-not really. But learning-yes, sort of. Survival again, and some basic manual skills: such as getting various tubes into the right places; a bit of light stitching; and of course the ritual appendicectomy, then offered to house surgeons as a kind of treat and exit examination.

Survival stratagems varied. Alcohol came into it-for reasons that would make immediate sense to whoever it was who once said that the quickest way out of Manchester was drink. And sometimes falling mildly in love with whichever student nurse was doing her charge nights made the summons from bed to ward a little more bearable. A few of us cracked up. No one I knew killed themselves-at least not at that stage.

By today's standards our patients were few. We looked after at most 50 or 60 , we knew them, and some of them even worried about us. One or two ventured to tell me I might not be getting enough sleep, and working men on hourly wages sometimes asked if we got overtime. We didn't.

But training? There was almost no formal teaching. We learnt the then current fashions in investigation, diagnosis, and treatment, particularly those cherished by our seniors. We read a little, and were guided rather than taught by senior house officers and registrars, who were more experienced but no better trained than we were. And we learnt from our mistakes.

Of course things have changed since then, though change is not invariably to be equated with progress. And of course there is need for a proper debate about the hours and training required to turn pale young medical graduates into half-credible consultants; but when there is talk of hours in training, it is quite important to know just exactly what is meant.

Colin Douglas doctor and novelist, Edinburgh 